\title{
Synthesis and biological analysis of a new curcumin analogue for enhanced anti-tumor activity in HepG 2 cells
}

\author{
JIAN XIAO $^{1 *}$, YANHUI CHU ${ }^{2 *}$, KEQIONG HU $^{1}$, JIN WAN $^{1}$, YI HUANG $^{1}$, \\ CHENGXI JIANG ${ }^{1}$, GUANG LIANG ${ }^{1}$ and XIAOKUN LI ${ }^{1}$
}

\author{
${ }^{1}$ Key Laboratory of Biotechnology Pharmaceutical Engineering, School of Pharmaceutical Science, Wenzhou Medical \\ College, Wenzhou 325035; ${ }^{2}$ Heilongjiang Province Key Laboratory of Anti-fibrosis Biotherapy, \\ Mudanjiang Medical College, Mudanjiang, Heilongjiang 157011, P.R. China
}

Received November 20, 2009; Accepted January 14, 2010

DOI: $10.3892 /$ or_00000781

\begin{abstract}
The aim of the present study was to investigate the apoptosis of human hepatocellular carcinoma cell line HepG 2 induced by a new curcumin analogue, GL63. HepG 2 cells were treated with increasing doses of GL63 and curcumin for $48 \mathrm{~h}$. The proliferation of cells was detected with MTT. The apoptosis were examined by flow cytometry. The caspase-3 activity was detected by Western blotting. ER calcium stores were assessed by the fluorescent calcium indicator fura-2/ AM. The protein expression of ER stress pathway, GRP78, XBP-1, ATF-4 and CHOP were examined with Western blotting. Growth inhibitory effect was observed for treatment with GL63 in a dose-dependent manner and with more potential than curcumin. GL63 at $20 \mu \mathrm{M}$ induced significant apoptosis in HepG 2 cells. Furthermore, GL63 induced the ER stress response, up-regulation of CHOP, XBP-1, ATF-4 and GRP78 expression in a dose-dependent, while curcumin had no effect on ER stress. These results suggest that GL63 has more potent anti-tumor activity than curcumin, which is associated with activation of ER stress and induction of apoptosis in HepG 2 cells.
\end{abstract}

\section{Introduction}

Hepatocellular carcinoma is one of the most common cancers worldwide, and it has become the first among malignant tumors in China (1). The outcomes of current available chemo-

Correspondence to: Dr Xiaokun Li, Key Laboratory of Biotechnology Pharmaceutical Engineering, School of Pharmaceutical Science, Wenzhou Medical College, Chashan College Park, Wenzhou City, Zhejiang 325035, P.R. China

E-mail: xiaokunli@163.net

${ }^{*}$ Contributed equally

Abbreviations: ER, endoplasmic reticulum; UPR, unfold protein response; Cur, curcumin

Key words: curcumin analogue, apoptosis, endoplasmic reticulum stress therapy drugs are poor, development of innovative new therapeutics for the management of liver cancer is especially urgent and this development is the long-term objective of this current project.

An increasing amount of attention has been paid to the use of complementary and alternative medicine as a part of the treatment for various cancers and the complications associated with current therapies (2). Curcumin, is a wellknown food additive and constituent of traditional medicine, which has long been used to treat various inflammatory diseases in China and India (3). It has a surprisingly wide range of beneficial properties, including anti-inflammatory, antioxidant, chemopreventive and chemotherapeutic activity and has been used to treat different cancer types including liver cancer in clinical trials (4). However, the exact molecular mechanisms involved in the apoptotic effect of curcumin remain to be identified. A number of studies suggest that multiple mechanisms may be involved in different cancer cell lines (5-7). Recently, it has been reported that curcumin exerts its pro-apoptotic effect by inducing endoplasmic reticulum stress (ER stress) in human leukemia HL-60 cells (8). Although curcumin is remarkably non-toxic and has promising anti-cancer activities, preclinical and clinical studies indicate that its poor bioavailability and pharmacokinetic profiles due to its instability under physiological conditions have limited its application in anti-cancer therapies (9-11).

Great effort has been put into the chemical modification of curcumin to identify potential analogues with better bioavailability and anti-tumor activities (7,12-16). We also have designed and synthesized a series of mono-carbonyl analogues of curcumin by deleting the reactive $\beta$-diketone moiety (17-20). Our preliminary studies indicate that some mono-carbonyl analogues not only have enhanced stability and anti-tumor activities in vitro but also have better pharmacokinetic profiles in vivo. However, the underlying cellular/molecular mechanisms by which these new analogues suppress cancer cell growth are unknown.

Literature data suggest that the stability and metabolic profiles of curucumin could be enhanced by deleting the Bdiketone moiety, and some curcumin analogues containing a 5-carbone enone spacer without $\beta$-diketone had been reported to retain or increase anti-tumor activity $(21,22)$. In the present investigation, we synthesized a new curcumin analogues, 


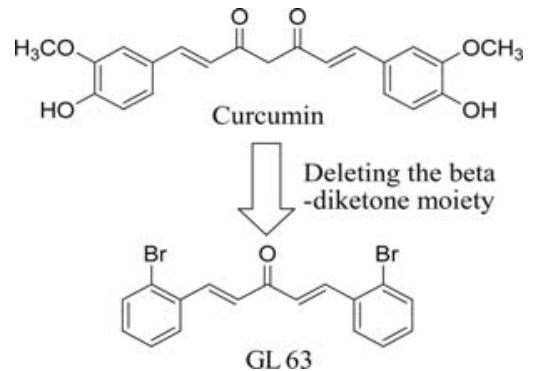

Figure 1. Schematic presentation of the synthesis of GL63.

(1E,4E)-1,5-bis(2-bromophenyl)penta-1,4-dien-3-one (GL63) and compared the effect of GL63 and curcumin in preclinical model systems using liver cancer cell lines (HepG 2) at several doses on cell growth, apoptosis and protein expression on ER stress pathway. We demonstrated that GL63, as a new curcumin analogue, is more active than curcumin in the inhibition of HepG 2 cells proliferation and induction of apoptosis. GL63 appears to be more potent than curcumin in anti-tumor activity and has more stability in pharmacokinetic profiles. Therefore, the synthetic derivative of curcumin GL63 has potential as a new therapeutic agent for hepatoma.

\section{Materials and methods}

Synthesis of GL63. The general procedure of synthesis of GL63 was as follows. An amount of $7.5 \mathrm{mmol}$ acetone was added to a solution of $15 \mathrm{mmol}$ arylaldehyde in $\mathrm{MeOH}(10 \mathrm{ml})$. The solution was stirred at room temperature for $20 \mathrm{~min}$, followed by dropwise addition of $\mathrm{NaOCH}_{3} / \mathrm{CH}_{3} \mathrm{OH}(1.5 \mathrm{ml}$, $7.5 \mathrm{mmol}$ ). The mixture was stirred at room temperature and monitored with TLC. When the reaction was finished, the residue was poured into saturated $\mathrm{NH}_{4} \mathrm{Cl}$ solution and filtered. The precipitate was washed with water and cold ethanol, and dried in vacuum. The solid was purified by chromatography over silica gel using $\mathrm{CH}_{2} \mathrm{Cl}_{2} / \mathrm{CH}_{3} \mathrm{OH}$ as the eluent to yield compounds.

Treatment of HepG 2 with GL63 and curcumin. Hepatocellular carcinoma cell line HepG 2 obtained from American Type culture Collection was grow in DMEM medium, containing $10 \%$ fetal bovine serum $100 \mathrm{U} / \mathrm{ml}$ penicillin and $100 \mu \mathrm{g} / \mathrm{ml}$ streptomycin at $37^{\circ} \mathrm{C}$ with $5 \% \mathrm{CO}_{2}$. GL63 and curcumin were dissolved in DMSO. The cells were treated with various concentrations $(5,10$ and $20 \mu \mathrm{M})$ of GL63 and curcumin for $48 \mathrm{~h}$. Control cultures were treated with DMSO and were processed similarly.

MTT assay. HepG 2 cells and rat primary culture hepatocytes were grow in a 96-well plate for $24 \mathrm{~h}$ and then treated with different doses $(5,10$ and $20 \mu \mathrm{M})$ of GL63 and curcumin for $48 \mathrm{~h}$, followed by the MTT treatment $(5 \mathrm{mg} / \mathrm{ml})$ to the cells in each well for $4 \mathrm{~h}$ at $37^{\circ} \mathrm{C}$ as described earlier. MTT was aspirated and $100 \mu \mathrm{l}$ of DMSO was added to each well and absorbance at $570 \mathrm{~nm}$ was read in a plate reader. Each treatment was done in triplicate. Mean of three values was determined and the results are expressed as percent of control.
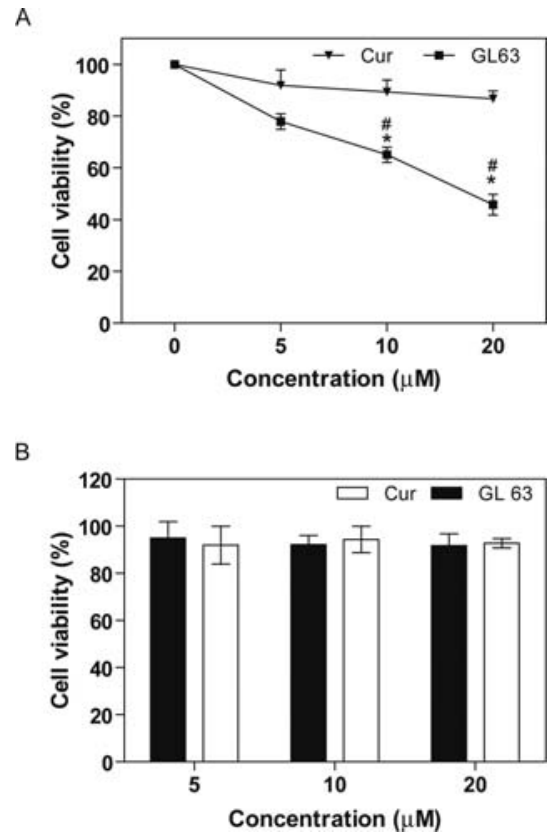

Figure 2. The effect of GL63 and curcumin on cell growth using (A) HepG 2 cells and (B) rat primary hypatocytes as determined by MTT assay. Percentage of control was quantitated from three independent experiments performed in triplicate. Mean of three values was determined and the results are expressed as percent of control. Data are presented as mean \pm SD. ${ }^{*}$ Statistically significant $(\mathrm{P}<0.05$, t-test) as compared with DMSO control. "Statistically significant $(\mathrm{P}<0.05, \mathrm{t}$-test $)$ as compared with curcumin group at the same concentration.

Apoptosis rate analysis. HepG 2 cells were grow for $24 \mathrm{~h}$ in a $6-\mathrm{mm}$ plate and then treated with varying doses $(5,10,20 \mu \mathrm{M})$ of GL63 and curcumin for $48 \mathrm{~h}$. Cells were washed by PBS 3 times, then digested by $0.25 \%$ tryptan-EDTA. After centrifugation, cells were resuspended in $0.5 \mathrm{ml}$ PBS. Cells were then stained with Annexin $\mathrm{V}$ and propidium iodide (PI) in the presence of $100 \mathrm{mg} / \mathrm{ml}$ RNAse and $0.1 \%$ Triton $\mathrm{X}-100$ for $30 \mathrm{~min}$ at $37^{\circ} \mathrm{C}$. Flow cytometric (BectonDickinson, Mountain, CA, USA) analysis was performed using a fluorescence-activated cell sorter.

Assay of endoplasmic reticulum calcium pools. HepG 2 cells were grow on $22 \times 40-\mathrm{mm}$ coverslips and treated with vehicle, curcumin and GL63 for $12 \mathrm{~h}$. The cells were loaded with $4 \mu \mathrm{M}$ fura-2 AM and $0.3 \%$ plurinic $\mathrm{F}-127$ in HBSS at $37^{\circ} \mathrm{C}$ for $120 \mathrm{~min}$ and incubated in HBSS for an additional $30 \mathrm{~min}$, then mounted on the stage of an Axioskop 2 plus upright fluorescence microscope (Carl Zeiss GmbH, Jena, Germany) equipped with a $\mathrm{x} 40$ objective. After washing with HBSS without $\mathrm{Ca}^{2+}$ and $\mathrm{Mg}^{2+}$ three times, cells were stimulated with thapsigargin (TG, $100 \mathrm{~nm}$; San Diego, CA, USA). Fluorescence images before and after addition of TG were collected at 15-sec intervals through a cooled CCD camera (TILL Photonics LLC, Martinsreid, Germany) which is attached to an image intensifier, an epifluorescent light source, a 515-nm dichroic beam splitter, and a 535-nm emission filter. The 340:380 ratios of individual cells in these images were analyzed using TILLvisION version 3.1 imaging software.

Western blotting. Caspase-3, GRP78, CHOP, XBP-1, ATF-4, Lamin B and Actin expression were examined by Western 
A

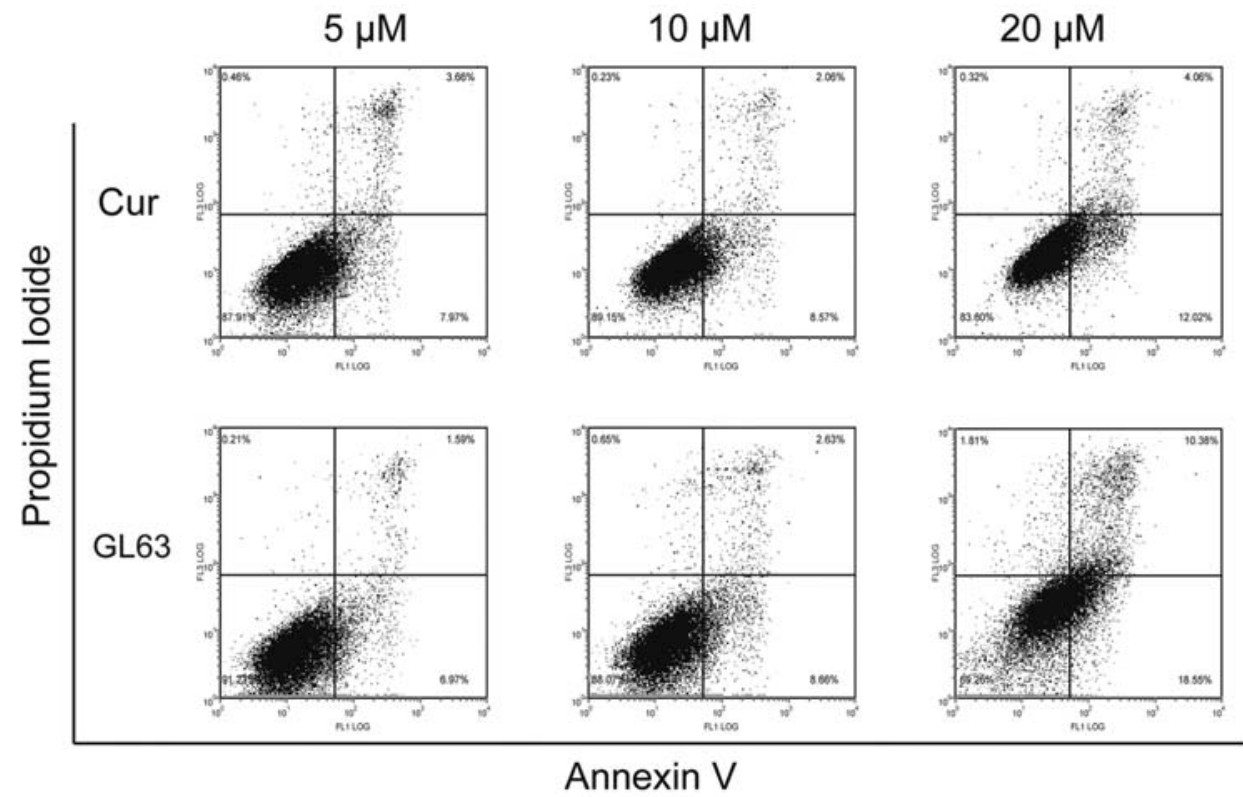

B

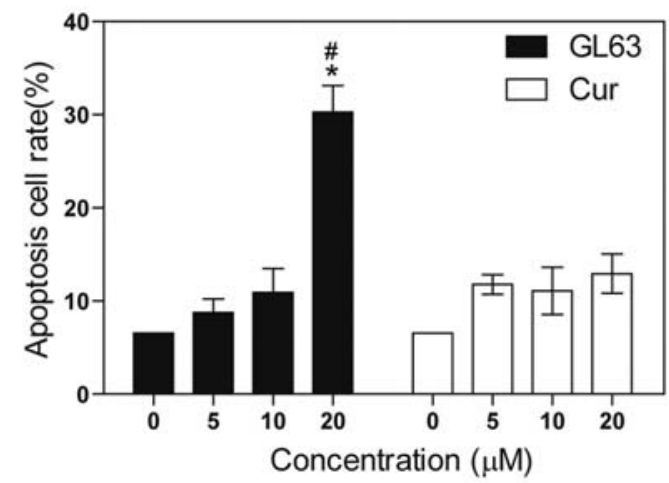

C

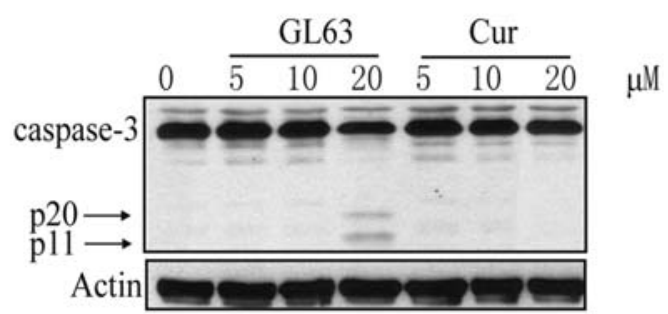

Figure 3. The effect of GL63 and curcumin on the induction of apoptosis using HepG 2 cells as determined by flow cytometry and protein expression of pre-caspase-3 and -9 analysis. (A) HepG 2 cells were treated with vehicle control (DMSO) or various amounts of GL63 (5, 10, $20 \mu \mathrm{M}$ ) or curcumin (5, 10, $20 \mu \mathrm{M}$ ) for $48 \mathrm{~h}$, then stained with Annexin V-FITC/propidium iodide, and detected by flow cytometry. (B) Bar diagram of apoptotic cell rate from three FACS analysis from three separate treatments. (C) Western blot analysis for apoptosis. Caspase-3 is shown in HepG 2 cell treated with GL63 (5, 10, $20 \mu$ M) or curcumin $(5,10,20 \mu \mathrm{M})$ for $48 \mathrm{~h}$. Actin was used as a protein loading control.

blot assay based on previous reports (8). Briefly, Cells were lysed, supernatants were collected, and proteins were resolved on Tris- $\mathrm{HCl}$ polyacrylamide gels at $120 \mathrm{~V}$. The proteins were transferred to a polyvinylidene difluoride (PVDF) blotting membrane, and the membranes were probed with rabbit polyclonal antibody (Santa Cruz, CA, USA). Details of the secondary antibodies used and their detection by chemiluminescence have been previously described (8). Equal loading was verified by determining protein concentration by Bio-Rad protein assay (Bio-Rad) and using the same amount of protein from protein lysates for electrophoretic analysis. B-actin was used as standard, and the ratio between the analyzed protein and $\beta$-actin from quantitative densitometric analysis was used for comparison of control and experimental samples.

Statistical evaluation. All assay were performed at least three times and levels of the parameters measured were expressed as mean \pm standard deviation (SD). Statistical comparisons between cells treatment with GL63 and curcumin versus control were based on the t-test.

\section{Results}

GL63 inhibits cancer cell viability more potently than curcumin. We determined the effect of GL63 and curcumin on cell proliferation in HepG 2 cells. GL63 significantly suppressed proliferation of HepG 2 cells dose-dependently in a 48-h treatment (Fig. 2A). In contrast, curcumin, even in $20 \mu \mathrm{M}$, showed $86 \%$ cell viability after $24 \mathrm{~h}$. To test the toxicity of curcumin analogues, rat primary culture hepatocytes were treated with GL63 and curcumin with $20 \mu \mathrm{M}$, neither GL63 nor curcumin affected the proliferation (Fig. 2B).

GL63 is more potent than curcumin in inducing apoptosis. At a sufficiently high dose, curcumin induces apoptosis of many cancer cells including liver cancer cells. We assessed the effect of GL63 and curcumin on the induction of apoptosis in HepG 2 cells by flow cytometry. The results (Fig. 3A and B) showed that GL63 dose-dependently increases cells apoptotic rate after $48 \mathrm{~h}$ treatment, GL63 at $20 \mu \mathrm{M}$ significantly induce apoptosis (30\%) compared with curcumin (13\%). Caspase-3 is a key effector molecule in the apoptosis pathway involved in 
A

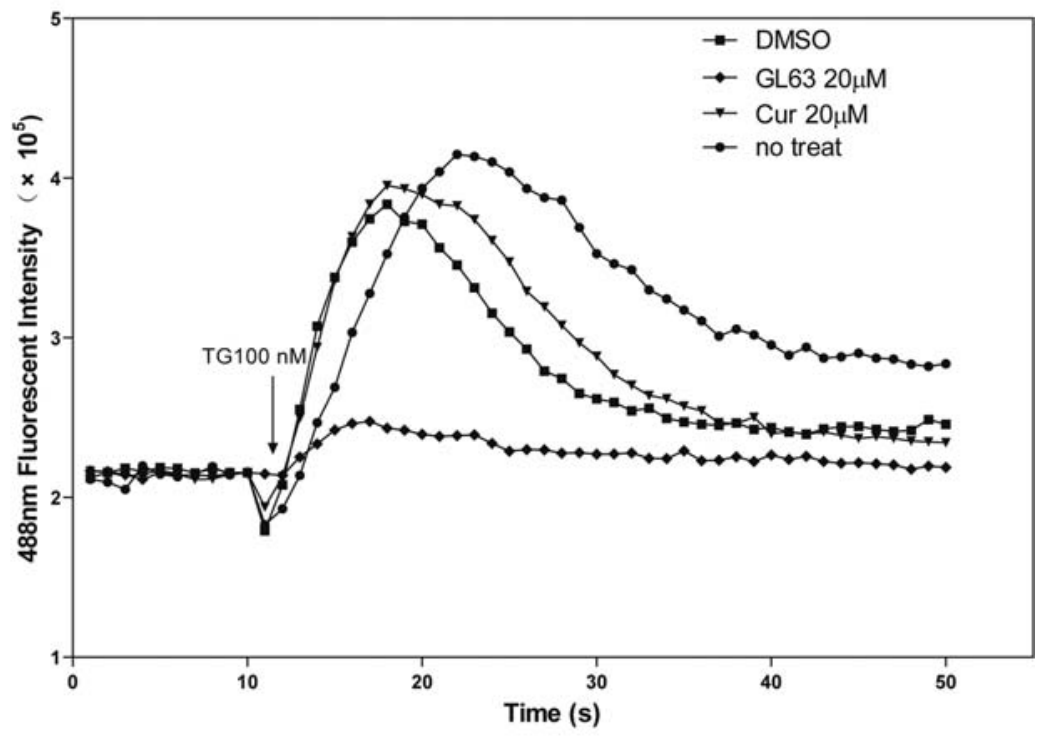

B

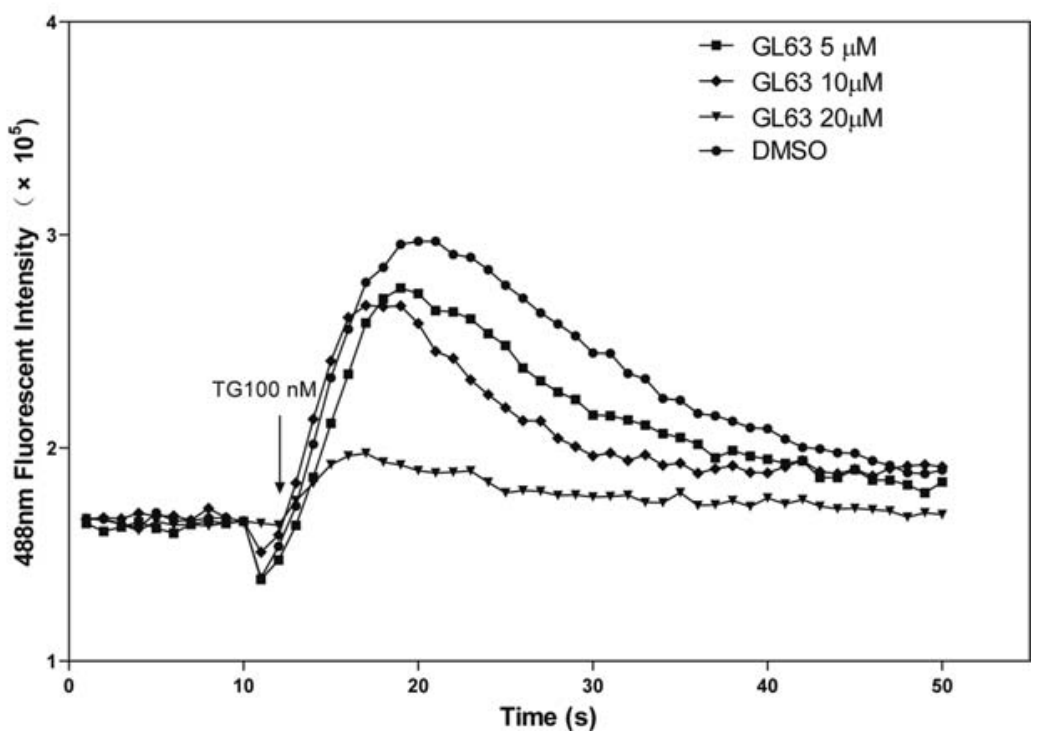

Figure 4. Depletion of endoplamic reticulum calcium stores by GL63 and curcumin. (A) Assessment of ER calcium stores in HepG 2 cells treated for 12 h with curcumin $(20 \mu \mathrm{M})$ and GL63 $(20 \mu \mathrm{M})$. Representative tracings of the Fura-2 fluorescence ratio of 340:380 nm in an individual cell for each treatment group before and after addition of $100 \mathrm{nM}$ thapsgargin are show. (B) Assessment of ER calcium stores in HepG 2 cells treated for $12 \mathrm{~h}$ with different concentrations of $\operatorname{GL} 63(5,10,20 \mu \mathrm{M})$.

amplifying the signal from initiator caspases, such as caspase- 8 and -12 . Increased activation of caspase- 3 was observed within $24 \mathrm{~h}$ in HepG 2 cells treated with $20 \mu \mathrm{M}$ GL63, however, curcumin did not induce caspase-3 activation (Fig. 3C). These data suggest that GL63 is a potent inducer of apoptosis even at low dose where no such effect is observed with curcumin.

Depletion of ER calcium stores by GL63. Depletion of luminal ER calcium stores is believed to reflect ER stress, which can promote induction of ER stress. To investigate the possible mechanisms of curcumin and GL63 induced ER stress and activation of the unfold protein response (UPR), we assessed the effect of GL63 and curcumin on ER calcium stores in HepG 2 cells with the fluorescent calcium indicator
fura-2/AM. After treatment with different concentration of curcumin and GL63, for $12 \mathrm{~h}$, cells were loaded with fura-2/ $\mathrm{AM}$ and swithed to calcium-free medium. ER calcium release induced by $100 \mathrm{nM}$ thapsigargin was recorded by fluorescence microscopy. Treatment of HepG 2 cells with GL63 decreased the ER calcium content in a dose-dependent manner. Cells treated with $20 \mu \mathrm{M}$ GL63 remarkably reduced the response to $\mathrm{TG}$, which suggested that ER calcium stores were depleted (Fig. 4B). However curcumin even at $20 \mu \mathrm{M}$ had similar effects on ER calcium stores (Fig. 4A).

Activation of the ER stress pathway by GL63. Recently, a novel pathway of cell apoptosis via ER stress has been reported. Inductions of the downstream transcription factors, GRP78, XBP-1, ATF-4 and CHOP, are markers for activation 
A
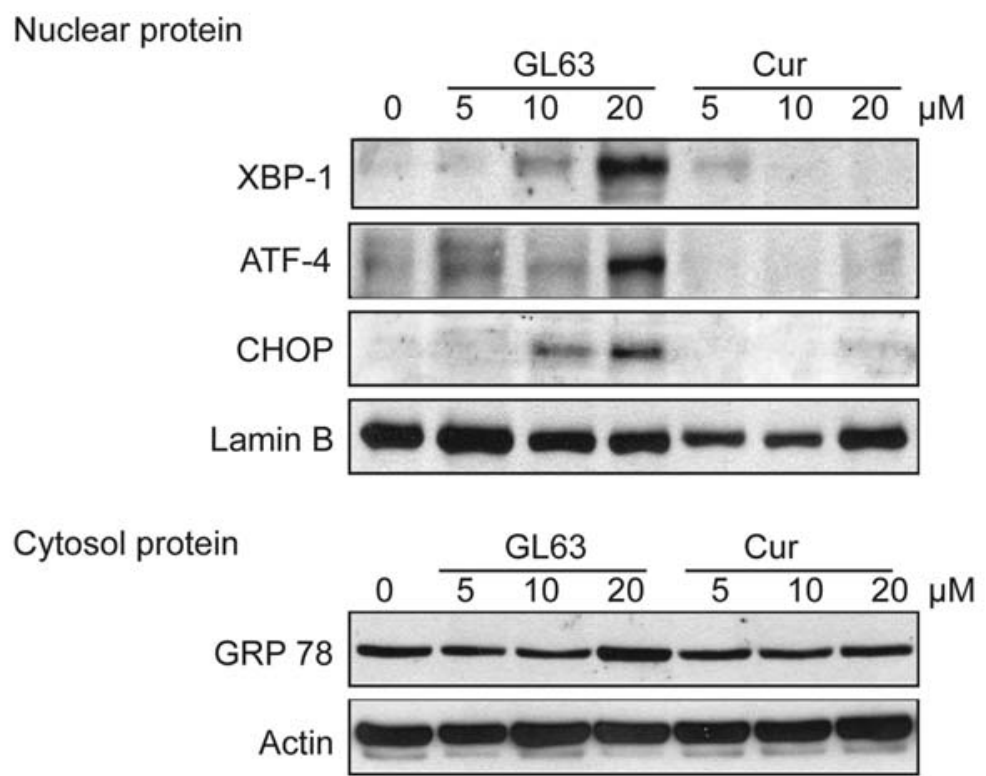

B
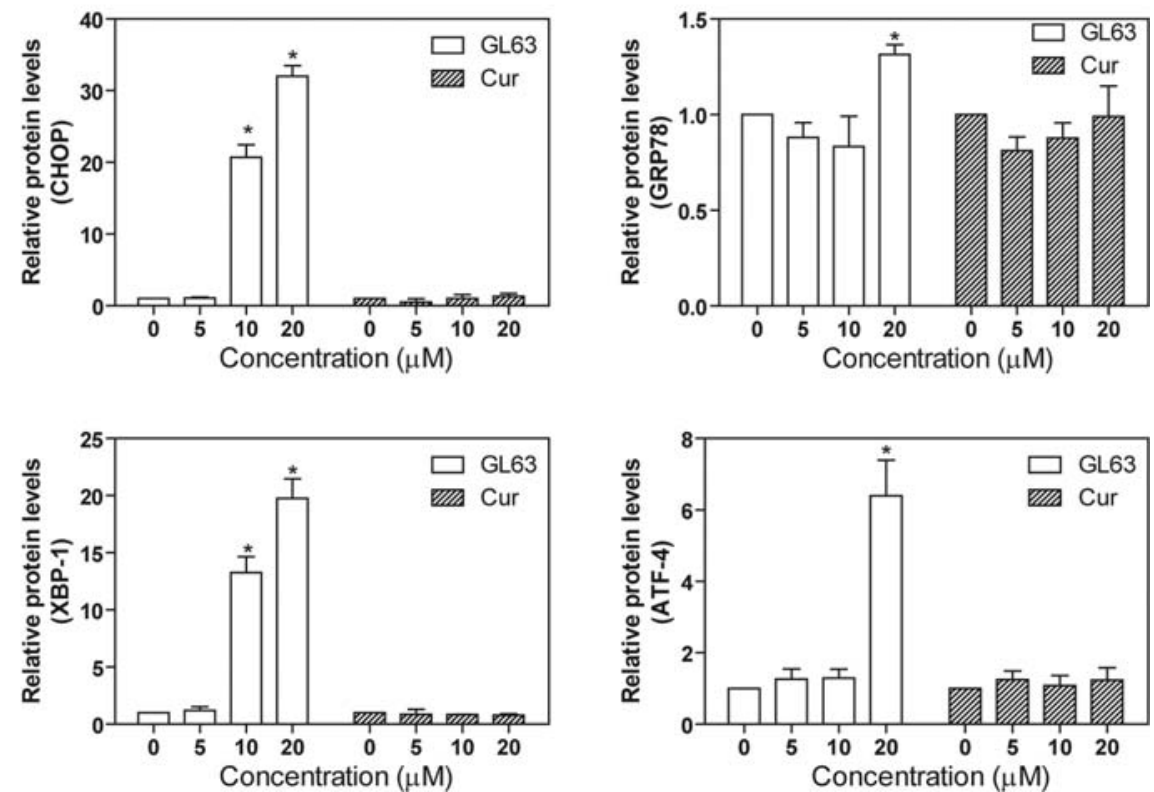

Figure 5. Concentration-dependent activation of ER stress pathway in HepG 2 cells. Representative immunoblots of GRP78, CHOP, ATF-4, XBP-1 from the nuclear extracts of H460 cells treated with GL63, curcumin $(5,10,20 \mu \mathrm{M})$, for $48 \mathrm{~h}$. Actin and Lamin B were used as a loading control. (B) Bar diagram of apoptotic cell rate from three Western blot analysis from three separate treatments. Data are presented as mean \pm SD. ${ }^{*}$ Statistically significant $(\mathrm{P}<0.05$, t-test $)$ as compared with DMSO control. "Statistically significant $(\mathrm{P}<0.05, \mathrm{t}$-test $)$ as compared with curcumin group at the same concentration.

of the UPR. In this study, we compared the effect of GL63 and curcumin on the UPR activation in HepG 2 cells. The results indicated that even though GL63 and curcumin inhibited cell growth, only GL63 induced the ER stress response in HepG 2 cells and the earliest response was observed at $6 \mathrm{~h}$ of treatment. As shown in Fig. 5, GL63 significantly induced the expression of GRP78, CHOP, ATF-4 and XBP-1 in a dose-dependent manner in HepG 2 cells. However, curcumin had no effect even at $20 \mu \mathrm{M}$ concentration. These results suggest that B19-induced UPR activation may represent a major cellular mechanism of its anti-cancer activity.

\section{Discussion}

Because curcumin is poorly absorbed through the gut, more potent and soluble curcumin analogues have been developed (9). In our previous study (17-20), a series of monocarbonyl analogues of curcumin was designed by the deletion of the highly reactive $\beta$-diketone moiety in the structure of curcumin which is considered to be responsible for the in vitro instability and the in vivo pharmacokinetic disadvantages. In this study, we also showed a new curcumin analogue GL63 significantly inhibit hepatocellular carcinoma cells proliferation and induce cell 
apoptosis, but curucmin at the same doses did not have a therapeutic effect.

Synthetic chemical analogues to molecularly targeted chemotherapeutic drugs are a common way to develop new drugs. These events include the acquisition of self-sufficient growth signals, insensitivity to signals that usually inhibit proliferation, use of a survival pathway to evade apoptosis, initiation of angiogenesis to ensure sufficient oxygen and nutrient significantly higher levels of apoptosis. There are several curcumin analogues that have already been reported, such as dimethoxycurcumin and EF-24 (21-23). We compared the inhibitory efficacy of GL63 and curcumin in HepG 2 cells. We demonstrated that GL63 are more potent than curcumin in the inhibition of cell viability in HepG 2 cells studied. Curcumin has been found to be safe in clinical trials and dose-limiting toxicity was not observed in many studies. We also observed that neither GL63 nor curcumin induced apoptosis in normal liver cells, which indicates that GL63 has no significant toxicity, similar to curcumin. Further, it will be necessary to evaluate the possible toxicity of GL63 comparing to curcumin in an animal model to verify the toxicity in vivo.

In this study it was also found that GL63 induced apoptosis in HepG 2 cells. GL63 is also more potent than curcumin in the induction of caspase- 3 and -9 , evidence of apoptosis. Two different pathways, the death receptor pathway and the mitochondrial pathway play major roles in regulating apoptosis in cancer cells. The caspase family includes critical mediators of apoptosis. The death receptor pathway and the mitochondrial pathway initially start by activation of caspase- 8 and -9 , respectively. Both the activated caspase -8 and -9 activate caspase- 3 and finally induce apoptosis. In the present study, it was found that caspase- 3 was activated in HepG 2 cells treated with GL63, while curcumin had no significant effect. This suggests that GL63 might induce apoptosis via a pathway that is mediated by the caspase signal pathway.

A recent study found that intracellular organelles, including the ER, promote cell apoptosis signals. The UPR is an intracellular signaling pathway, which regulates the accumulation of unfolded or misfolded proteins in the ER and plays and important role in regulating cell growth, differentiation and apoptosis (24-26). Therefore, the possibility that GL63 induces apoptosis via ER stress was examined. $\mathrm{CHOP}$ is a typical ER stress-regulated protein involved in ER stress-induced apoptosis. Our results on CHOP induction by GL63 suggest that GL63 may trigger ER stress. Indeed, GL63 also increased the levels of XBP-1, ATF-4, GRP78, all of which are additional proteins increased during ER stress. However, curcumin at the same concentration had no effect on GRP78, CHOP, ATF-4 and XBP-1, suggesting that curcumin-inhibited hepatocellular carcinoma growth does not involve ER stress. Although some studies showed curcumin-induced ER stress in human leukemia HL-60 cells, murine melanoma B16-F10 cells, and lung cancer cells A549 $(8,27,28)$, the concentration of curcumin was higher than in our studies.

The ER is a principal site of the synthesis for protein, sterols, cholesterol, and other lipids. Maintenance of ER calcium homeostasis is essential for many cellular functions. Perturbation of ER calcium homeostasis is expected to induce
ER stress. Thapsigargin depletes the ER calcium stores and activates the UPR in many mammalian cells (29). We assessed the effect of GL63 on the mobilization of $\mathrm{Ca}^{2+}$. Treatment with GL63 resulted in a rapid increase in cytosolic calcium levels as early as $12 \mathrm{~h}$ after GL63 in HepG 2 cells.

In conclusion, our studies show that the new monocarbonyl analogue of curcumin, GL63 treatment, of NSCLC cancer cells results in growth inhibition in vitro. Our studies in combination with the observation that GL63 did not affect proliferation of normal liver cells strongly suggest that GL63 has potential for use as a therapeutic or chemo-preventative agent for liver cancer. GL63 activation of ER stress may contribute to the anti-cancer activity. The enhanced potency and better pharmacokinetic profiles renders it a strong candidate for therapeutic applications for hepatocellular carcinoma, possibly also other cancers.

\section{Acknowledgements}

This study was supported by the National Natural Science Funding of China (30901819); the Science Foundation of Zhejiang Province of China (Y2090668); the Department of Education science grant of Zhejiang Province (20070992) and and funds from the Zhejiang Provincial Extremely Key Subject Building Project 'Pharmacology and Biochemical Pharmaceutics 2008'.

\section{References}

1. Gu D, Kelly TN, Wu X, Chen J, Samet JM, Huang JF, Zhu M, Chen JC, Chen CS, Duan X, Klag MJ and He J: Mortality attributable to smoking in China. N Engl J Med 360: 150-159, 2009.

2. Lev-Ari S, Lichtenberg D and Arber N: Compositions for treatment of cancer and inflammation. Recent Pat Anticancer Drug Discov 3: 55-62, 2008.

3. Strimpakos AS and Sharma RA: Curcumin: preventive and therapeutic properties in laboratory studies and clinical trials. Antioxid Redox Signal 10: 511-545, 2008

4. Hatcher H, Planalp R, Cho J, Torti FM and Torti SV: Curcumin: from ancient medicine to current clinical trials. Cell Mol Life Sci 65: 1631-1652, 2008.

5. Freudlsperger C, Greten J and Schumacher U: Curcumin induces apoptosis in human neuroblastoma cells via inhibition of nfkappab. Anticancer Res 28: 209-214, 2008.

6. Javvadi P, Segan AT, Tuttle SW and Koumenis C: The chemopreventive agent curcumin is a potent radiosensitizer of human cervical tumor cells via increased reactive oxygen species production and overactivation of the mitogen-activated protein kinase pathway. Mol Pharmacol 73: 1491-1501, 2008.

7. Subramaniam D, May R, Sureban SM, Lee KB, George R, Kuppusamy P, Ramanujam RP, Hideg K, Dieckgraefe BK, Houchen CW and Anant S: Diphenyl difluoroketone: a curcumin derivative with potent in vivo anticancer activity. Cancer Res 68: 1962-1969, 2008.

8. Pae HO, Jeong SO, Jeong GS, Kim KM, Kim HS, Kim SA, Kim YC, Kang SD, Kim BN and Chung HT: Curcumin induces pro-apoptotic endoplasmic reticulum stress in human leukemia hl-60 cells. Biochem Biophys Res Commun 353: 1040-1045, 2007.

9. Anand P, Kunnumakkara AB, Newman RA and Aggarwal BB: Bioavailability of curcumin: problems and promises. Mol Pharm 4: 807-818, 2007.

10. Appiah-Opong R, de Esch I, Commandeur JN, Andarini M and Vermeulen NP: Structure-activity relationships for the inhibition of recombinant human cytochromes $\mathrm{p} 450$ by curcumin analogues. Eur J Med Chem 43: 1621-1631, 2008.

11. Sharma RA, Steward WP and Gescher AJ: Pharmacokinetics and pharmacodynamics of curcumin. Adv Exp Med Biol 595: 453-470, 2007. 
12. Wang X, Lin J, Chen Y, Zhong W, Zhao G, Liu H, Li S, Wang L and Li S: Novel fatty acid synthase (fas) inhibitors: design, synthesis, biological evaluation, and molecular docking studies. Bioorg Med Chem 17: 1898-1904, 2009.

13. Selvam C, Jachak SM, Thilagavathi R and Chakraborti AK: Design, synthesis, biological evaluation and molecular docking of curcumin analogues as antioxidant, cyclooxygenase inhibitory and anti-inflammatory agents. Bioorg Med Chem Lett 15: 1793-1797, 2005.

14. Ohori H, Yamakoshi H, Tomizawa M, Shibuya M, Kakudo Y, Takahashi A, Takahashi S, Kato S, Suzuki T, Ishioka C, Iwabuchi $\mathrm{Y}$ and Shibata H: Synthesis and biological analysis of new curcumin analogues bearing an enhanced potential for the medicinal treatment of cancer. Mol Cancer Ther 5: 2563-2571, 2006.

15. Mosley CA, Liotta DC and Snyder JP: Highly active anticancer curcumin analogues. Adv Exp Med Biol 595: 77-103, 2007.

16. Liang G, Li X, Chen L, Yang S, Wu X, Studer E, Gurley E, Hylemon PB, Ye F, Li Y and Zhou H: Synthesis and antiinflammatory activities of mono-carbonyl analogues of curcumin Bioorg Med Chem Lett 18: 1525-1529, 2008.

17. Liang G, Yang SL, Shao LL, Zhao CG, Xiao J, Lv YX, Yang J, Zhao Y and Li XK: Synthesis, structure, and bioevaluation of 2,5-bis(arylmethenyl)cyclopentanones. J Asian Nat Prod Res 10: $957-965,2008$

18. Liang G, Yang S, Zhou H, Shao L, Huang K, Xiao J, Huang Z and Li X: Synthesis, crystal structure and anti-inflammatory properties of curcumin analogues. Eur J Med Chem 44: 915-919, 2009.

19. Liang G, Yang S, Jiang L, Zhao Y, Shao L, Xiao J, Ye F, $\mathrm{Li} \mathrm{Y}$ and Li X: Synthesis and anti-bacterial properties of monocarbonyl analogues of curcumin. Chem Pharm Bull (Tokyo) 56: $162-167,2008$

20. Liang G, Shao L, Wang Y, Zhao C, Chu Y, Xiao J, Zhao Y, $\mathrm{Li} X$ and Yang S: Exploration and synthesis of curcumin analogues with improved structural stability both in vitro and in vivo as cytotoxic agents. Bioorg Med Chem 17: 2623-2631, 2009

21. Sun A, Shoji M, Lu YJ, Liotta DC and Snyder JP: Synthesis of EF24-tripeptide chloromethyl ketone: a novel curcumin-related anticancer drug delivery system. J Med Chem 49: 3153-3158, 2006.
22. Adams BK, Cai J, Armstrong J, Herold M, Lu YJ, Sun A Snyder JP, Liotta DC, Jones DP and Shoji M: EF24, a novel synthetic curcumin analog, induces apoptosis in cancer cells via a redox-dependent mechanism. Anticancer Drugs 16: 263-275, 2005 .

23. Pae HO, Jeong SO, Kim HS, Kim SH, Song YS, Kim SK, Chai KY and Chung HT: Dimethoxycurcumin, a synthetic curcumin analogue with higher metabolic stability, inhibits no production, inducible no synthase expression and NF-kappaB activation in raw264.7 macrophages activated with IPS. Mol Nutr Food Res 52: 1082-1091, 2008.

24. Zou W, Yue P, Khuri FR and Sun SY: Coupling of endoplasmic reticulum stress to CDDO-me-induced up-regulation of death receptor 5 via a chop-dependent mechanism involving JNK activation. Cancer Res 68: 7484-7492, 2008.

25. Zhang K and Kaufman RJ: Signaling the unfolded protein response from the endoplasmic reticulum. J Biol Chem 279: 25935-25938, 2004.

26. Oyadomari S and Mori M: Roles of chop/gadd153 in endoplasmic reticulum stress. Cell Death Differ 11: 381-389, 2004.

27. Bakhshi J, Weinstein L, Poksay KS, Nishinaga B, Bredesen DE and Rao RV: Coupling endoplasmic reticulum stress to the cell death program in mouse melanoma cells: effect of curcumin. Apoptosis 13: 904-914, 2008.

28. Lin SS, Huang HP, Yang JS, Wu JY, Hsia TC, Lin CC, Lin CW, Kuo CL, Gibson Wood W and Chung JG: DNA damage and endoplasmic reticulum stress mediated curcumininduced cell cycle arrest and apoptosis in human lung carcinoma A549 cells through the activation of caspases cascade- and mitochondrial-dependent pathway. Cancer Lett 272: 77-90, 2008.

29. Yamaguchi H and Wang HG: Chop is involved in endoplasmic reticulum stress-induced apoptosis by enhancing DR5 expression in human carcinoma cells. J Biol Chem 279: 4549545502,2004 